\title{
No muro, na roupa, na pele: o personagem na paisagem urbana
}

ON WALLS, ON CLOTHING, ON THE SKIN: THE CHARACTER IN THE URBAN LANDSCAPE

\section{João Batista Cardoso}

Doutor em Comunicação e Semiótica pela Pontifícia Universidade Católica de São Paulo (PUCSP) com pós-doutorado pela Escola de Comunicações e Artes da Universidade de São Paulo (ECA-USP). Professor do Programa de Mestrado em Comunicação da Universidade Municipal de São Caetano do Sul (USCS).

jbfcardoso@uol.com.br

Recebido em 27 de fevereiro de 2016. Aprovado em 9 de maio de 2016.

\section{Resumo}

Este artigo discute os diferentes modos de exibição das imagens de personagens de histórias em quadrinhos no ambiente urbano. Apesar de protegidas por copyright, essas imagens são ostentadas indevidamente em locais públicos. Esse tipo de apropriação visa a difundir discursos variados, que envolvem desde posicionamentos políticos a relatos pessoais. Tais discursos materializam-se em suportes provisórios e permanentes: muros, fachadas, veículos e, até mesmo, no próprio corpo humano que transita pela cidade. Ainda que tenham caráter subversivo, essas práticas revelam modos criativos de falar sobre a cidade e o cidadão.

Palavras-chave: Ambiente urbano. Personagem. Apropriação.

\section{Abstract}

This article discusses the different ways of exhibiting images of comic book characters in the urban environment. In spite of copyright rules, these images are unduly displayed in public places. This type of appropriation aims to spread a wide range of discourses, from political positions to personal accounts. Such discourses are materialized on temporary and permanent supports: walls, facades, vehicles and even the human body that moves around the city. Although these displays are of a subversive nature, these practices reveal creative ways of talking about the city and its citizens.

Keywords: Urban environment. Character. Appropriation. 


\section{Introdução}

Este texto é um desmembramento da pesquisa "Personagem em tatuagem: transposição das páginas das histórias em quadrinhos para o corpo humano"1, que investiga como o portador de tatuagens de personagens de histórias em quadrinhos faz uso desse tipo de signo para narrar suas histórias e construir sua identidade. Neste artigo, procura-se discutir os diferentes modos de apropriação e exposição das figuras de personagens no ambiente urbano.

Interessa a este estudo o uso das imagens de personagens veiculados em narrativas impressas ou audiovisuais do século XX, pois compreendemos que eles revelam uma prática de apoderamento das produções midiáticas que tem como intuito a difusão de discursos individuais ou coletivos, envolvendo desde posicionamentos políticos a reflexões sobre o comportamento social. Assim, é relevante para a discussão observar, especificamente, os modos de apropriação que estão relacionados às práticas subversivas: reprodução, comercialização e uso indevido de imagens protegidas por copyright; alteração da forma e violação do caráter e dos valores das imagens.

Apesar de protegidas por copyright, essas imagens são utilizadas em manifestações diversas (comerciais, artísticas, políticas etc.) e ostentadas publicamente em painéis promocionais, grafites, estampas de roupas ou bandeiras de agremiações. Tais manifestações materializam-se pelas ruas das cidades em suportes provisórios ou permanentes, fixos ou móveis: muros, paredes, equipamentos urbanos, veículos, corpo humano etc.

Entendemos que, ainda que tenha caráter subversivo, essa prática revela modos criativos de falar sobre a cidade e o cidadão. Ao serem tirados de seus contextos e transpostos para outras mídias, os personagens adquirem novos sentidos e participam dos discursos da cidade.

\section{A cidade como espaço da comunicação e discurso}

Para Canevacci (2004, p. 43), a metrópole é o espaço propício para a comunicação visual: é o ambiente do olhar e do ser olhado. Há, nesse ecossistema, o "exagero de observar e ser observado". Assim, o cidadão se orienta pelas ruas fitando imagens e passeia pelos espaços urbanos contemplando e examinando figuras, ao mesmo tempo que atrai olhares. Alguns se produzem especialmente para atrair os olhares - formas e cores, nas

1 Auxílio: processo \#2014/21537-5, Fundação de Amparo à Pesquisa do Estado de São Paulo (Fapesp).

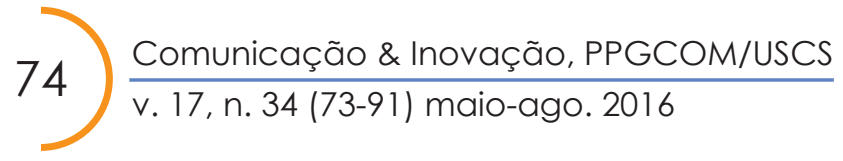


roupas e no corpo. Outros capturam o olhar alheio com sinais que deixam pelas ruas formas e cores, nos muros e nas vitrines.

As imagens na roupa e no corpo, nesse contexto, dizem um pouco sobre o sujeito que as porta. As imagens nas fachadas ou muros, por sua vez, dizem um pouco sobre a cidade que as exibe. Sob outra perspectiva, as imagens nas roupas e nos corpos, no fluxo do movimento urbano, dialogam com as imagens da cidade. Na foto de alguém que atravessa a esquina, a aparência da pessoa fala sobre a esquina assim como a vista da esquina fala sobre a figura que a cruza. Os significados e sentidos que surgem das relações entre as imagens das pessoas (ou as imagens nas pessoas) e as imagens da cidade (ou as imagens na cidade) eclodem das semelhanças e contrastes entre essas imagens, antagonismos e complementaridades nas relações figura e fundo. Para Canevacci (2004, p. 43), "a comunicação urbana exacerba essas diferenças, multiplica-as, fá-las coexistir e entrar em conflito". São composições de cores, formas, texturas e movimentos que refletem "modos de pensar, de sentir e de agir".

Para compreender essas relações, que se constituem pela movência, é preciso olhar as partes, os fragmentos, e estabelecer relações entre esses elementos. Neste estudo interessa um tipo particular de elemento: a figura de personagens de histórias em quadrinhos e animações audiovisuais - em especial, personagens veiculadas em revistas ou programas do século XX. A composição desse elemento com o corpo humano e com as partes da cidade apresenta-se como um sistema de codificação contemporâneo utilizado por grupos sociais específicos para falar sobre si e sobre a cidade.

Como afirma Lefebvre (2001, p. 63), "a Cidade emite e recebe mensagens. Essas mensagens são compreendidas ou não (codificam-se e se decodificam ou não)". Os diferentes sistemas de codificações que transitam e se espalham pelas cidades são desenvolvidos por comunidades específicas, muitas vezes, para comunidades específicas. Tais codificações implicam um sistema de significação e sentido que resulta em um sistema de valores, que são aceitos e compreendidos por determinados grupos e não por outros.

A linguagem urbana, para Lefebvre (2001, p. 64), se materializa nas práticas diárias, na vivência nos espaços, e é "aquilo que acontece na rua, nas praças, nos vazios, aquilo que aí se diz". Essas práticas diárias atualizam sistemas de codificação particulares a cada cidade ou comunidades que nela vivem e circulam, e são expressas, também, por meio das imagens que se espalham pelas ruas, no corpo do cidadão ou no corpo da própria cidade.

Nesse sentido, além do conjunto de codificação difundido pelos sistemas institucionais, há na cidade uma série de codificações promovidas por práticas ilegítimas codificações apócrifas que subvertem outros sistemas. Esse aspecto típico do objeto de estudo, a apropriação indevida de figuras de personagens do século XX, conduz a esta 
investigação. As apropriações de figuras licenciadas, por sistemas artísticos, políticos ou da moda, corporificam-se em grafites, vitrines, camisetas, tatuagens etc. Contudo, ainda que tais práticas possam ser consideradas subversivas, são socialmente produzidas e revelam interações criativas; rompem com as normas estabelecidas visando a criar novos padrões estéticos e a difundir discursos próprios sobre os indivíduos e sobre a cidade.

Para Silverstone (2014, p. 113),

a vida cotidiana implica contínuo movimento através de fronteiras e limiares: entre público e privado; o sagrado e o profano; o palco e os bastidores; as esferas do real e do fantástico; a realidade interna e a externa; o individual e o social".

Nessa estremadura se localizam as figuras de personagens apropriadas por sistemas subversivos: certos grupos tomam como domínio público imagens que possuem direito assegurados; usam signos difundidos pela mídia de massa para disseminar ideias particulares; buscam, por meio de referências do passado, se expressar sobre problemas contemporâneos; trazem para a rotina da cidade narrativas das indústrias do entretenimento. "Os significados mediados movem-se [...] através do espaço, e de espaços. Eles se movem do público para o privado, do globalizador para o local e o pessoal, e vice-versa" (Ibid., p. 36-37). Como lembra o autor, na sociedade pós-moderna tais fronteiras são recriadas diariamente - e, no caso específico do objeto aqui estudado, elas refletem uma forma de brincar com os produtos das mídias.

Há muitas maneiras de ver a mídia como lugar para a brincadeira, tanto em seus textos como nas respostas que eles engendram [...]. A mídia tem a capacidade (de fato, ela depende completamente dessa capacidade) de envolver o público em espaços e tempos distintos das - e delimitados em relação às - confusões da vida cotidiana, que sem isso seriam implacáveis. (Ibid., p. 116).

Essa forma de interação com os produtos midiáticos é natural da cultura popular, que sempre abriu espaço para a transgressão e o protesto. Os desfiles de carnaval, as festas de rua e os eventos de cosplay, por exemplo, corrompem normas cotidianas, muitas vezes opressoras, promovendo outras formas de comportamento em público, que estimulam espaços liminares que combinam a realidade com a fantasia (FEATHERSTONE, 1995). Ao trazer para o ambiente urbano discursos individuais ou coletivos, a apropriação de imagens licenciadas acaba por subverter os valores originais de personagens comerciais. Os muros, corpos ou roupas, nesse contexto, funcionam como mídia no processo de mediação. 
A mediação implica o movimento de significado de um texto para outro, de um discurso para outro, de um evento para outro. Implica a constante transformação de significados, em grande e pequena escala, importante e desimportante, à medida que textos da mídia e textos sobre a mídia circulam em forma escrita, oral e audiovisual, e à medida que nós, individual e coletivamente, direta e indiretamente, colaboramos para a sua produção. (SILVERSTONE, 2014, p. 33).

Ainda conforme Silverstone (2014, p. 34), “os significados mediados circulam em textos primários e secundários, através de intertextualidades infindáveis, na paródia e no pastiche, no constante replay e nos intermináveis discursos". Citando George Steiner, o autor lembra que a apropriação está relacionada diretamente a um processo de confian$c ̧ a$, porque "identificamos valor no texto de que estamos tratando, valor que queremos compreender, alegar e comunicar para os outros, para os nossos" (Ibid., p. 35). Mas, ao mesmo tempo, é um processo de agressão, pois, mesmo que exista a intensão de reafirmar os valores originais da imagem apropriada, existem entendimentos que são próprios e particulares. O paradoxo que caracteriza tal prática é justamente manifestar um afeto pelo personagem apropriado, ao mesmo tempo que se demonstra uma desconsideração por seus valores originais.

De qualquer modo, essa forma de expressão, que é traço da paisagem contemporânea nas cidades, reflete a identidade de certos grupos urbanos.

\section{O personagem fora da narrativa: signo de consumo e transgressão}

Ainda que esteja intimamente vinculado à palavra e à narrativa, o personagem de histórias em quadrinhos tem sua existência na imagem. São os caracteres visuais (suas formas, cores, roupas, expressões, gestos, poses etc.) que possibilitam ao personagem expressar uma ideia fora do contexto da narrativa (CARDOSO; SANTOS, 2015), de tal maneira que sua figura chega a produtos diversos sem vir acompanhada, muitas vezes, de um único signo verbal. Tal atributo faz que os personagens de histórias em quadrinhos sejam utilizados em negócios relacionados ao entretenimento (parque de diversão, brinquedo, game, figurinha colecionável etc.), a produções artísticas (pintura, escultura etc.) e a diversas áreas comerciais (licenciamento de produtos diversos, como vestuário, adereço, objeto de decoração, mobiliário, embalagem de alimento, material escolar, utensílio doméstico etc.).

De acordo com Gordon (1998), Yellow Kid, criado por Richard Outcault em 1895, foi o primeiro personagem de quadrinhos a desfrutar de popularidade e mostrar que esse 
tipo de imagem poderia ser utilizado para incrementar a venda de produtos. As tirinhas com o personagem aumentaram consideravelmente a tiragem do próprio jornal em que foi lançado, o Sunday World.

Visando a licenciar produtos com a imagem do personagem, Outcault tentou garantir a proteção de direito autoral, mas, antes disso, outros jornais já tinham copiado o personagem. Em pouco tempo e sem a autorização do autor, um série de produtos foram licenciados: livros musicais, chocolates, cigarros etc. Para Gordon (1998, p. 32, tradução nossa), "Yellow Kid demonstrou o potencial dos personagens para capturar a imaginação do público".

O caso Yellow Kid chamou a atenção de artistas e empresários do setor da comunicação para a importância de registro do copyright. Em 1902, Outcault criou e licenciou o personagem Buster Brown, que foi veiculado no New York Herald e, em pouco tempo, passou a estampar uma variedade de produtos. A imagem de Buster Brown passou a ser utilizada para atrair a atenção do consumidor norte-americano. Tal prática comercial revelou que o personagem poderia "transcender as histórias em quadrinhos para se tornar um ícone cultural” (Ibid., p. 37-38, tradução nossa).

O registro do personagem Buster Brown permitiu a Outcault licenciar uma variedade de produtos, que, em 1904, foram expostos na Feira Mundial de St. Louis: sapatos, relógios, tecidos, bebidas, cafés, pães, maçãs, pianos etc. No mesmo ano, motivados pelo aumento na venda de exemplares e visando a obter lucro no mercado publicitário, grande parte dos jornais estadunidenses passou a publicar suplementos dominicais com tirinhas em quadrinhos.

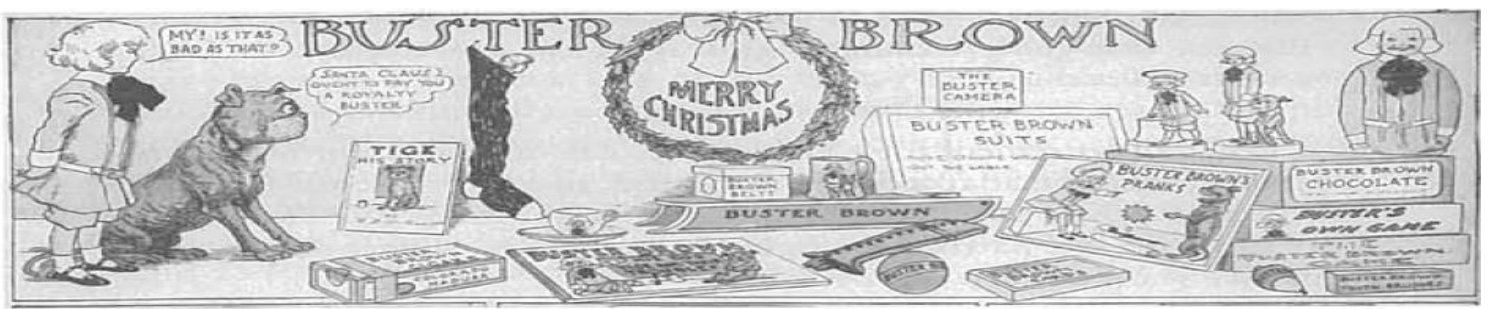

Figura 1. Produtos licenciados com a marca Buster Brown

Fonte: Gordon (1998, p. 56)

Os quadrinhos publicados nos jornais estadunidenses no início do século XX surgiam também como um fenômeno social que refletia a emergente cultura consumista da época (GORDON, 1998). Tal cultura era, em parte, derivada das oportunidades que as cidades ofereciam aos cidadãos de ver e ser vistos nos espaços públicos, nas áreas de entretenimento, no transporte coletivo etc. 
Nesse contexto, os personagens de histórias em quadrinhos colaboravam com a constituição da imagem desse novo consumidor e dessa nova cidade à medida que retratavam os costumes urbanos nas próprias histórias impressas e ilustravam fachadas de estabelecimentos comerciais e cartazes publicitários espalhados pelas ruas. A difusão das imagens dos personagens, para Gordon, reflete uma urbanização da cultura estadunidense, ou, ainda, uma fascinação com a experiência urbana. Assim, os quadrinhos participaram diretamente da transformação da cultura urbana, que não era marcada apenas pelo aumento do consumo de bens e serviços, mas também pelo consumo de bens simbólicos.

Nas décadas de 1920 e 1930, as empresas utilizaram ostensivamente as imagens de personagens para capturar a atenção do público, e essas ações comerciais tornaram as histórias em quadrinhos parte da vida diária nos Estados Unidos. Pesquisas conduzidas por George Gallup nesse período revelaram o potencial de venda de produtos por meio dos personagens de histórias em quadrinhos, o que motivou o uso dessa estratégia promocional no período da Grande Depressão estadunidense. A popularidade das revistas de histórias em quadrinhos entre os adultos, demonstrada pelas pesquisas de Gallup, sugeria que o gênero estaria se transformando em uma importante marca do modo de vida nos Estados Unidos. Gallup estudou 4.000 casos em seis jornais metropolitanos e chegou à seguinte conclusão: "professores, doutores, fazendeiros e advogados leem histórias em quadrinhos tanto quanto motoristas de caminhão, garçons ou diaristas" (GORDON, 1998, p. 86, tradução nossa).

Gordon relata que, nos primórdios das histórias em quadrinhos, parques de diversão já eram construídos com temáticas baseadas nos personagens - Katzenjammer Castle foi construído em Sant, Minnesota, na virada do século. Na primeira metade do século $\mathrm{XX}$, personagens originários das tirinhas dominicais ou revistas de histórias em quadrinhos já eram exibidos nas telas da televisão e cinema e nos palcos da Broadway. Na década de 1960 as referências das histórias em quadrinhos chegaram às artes, nos trabalhos de Roy Lichtenstein e Andy Warhol. "Personagens de tirinhas e revistas de histórias em quadrinhos haviam transpassado o meio de sua origem" (Ibid., p. 156, tradução nossa).

Dois aspectos que habilitam esse tipo de imagem a expressar sentido fora do contexto da narrativa são a configuração esquemática e o aspecto psíquico limitado dos personagens de quadrinhos (CARDOSO; SANTOS, 2015). Assim, quando não estão nas páginas de histórias em quadrinhos, em animações cinematográficas ou televisivas ou em games, as personagens apresentam-se, quase sempre, em uma pose ou expressão já conhecida ou em uma cena reproduzida da narrativa.

Atualmente, é comum encontrar pelas ruas reproduções de cenas, poses ou expressões de imagens de personagens antigos. Desde as últimas décadas do século XX, o 
estilo retrô impulsiona o uso de referências dos quadrinhos nos setores produtivo e cultural. Para Grainge (2000), a "nova politica dos velhos valores", promovida pelo presidente Ronald Reagan na década de 1980, e o crescimento da geração baby-boomer contribuíram para o desenvolvimento dessa tendência - contudo, um dos fatores principais, para o autor, foi a proliferação das inovações tecnológicas que permitiram resgatar, reciclar e reconfigurar o passado no terreno cultural e nos meios de comunicação. Tal prática interessa à mídia por ser uma maneira econômica de disponibilizar conteúdo.

Como um estilo cultural, a nostalgia se desenvolveu de acordo com uma série de fatores culturais, demográficos, tecnológicos e comerciais que fizeram do "passadismo" algo conveniente e comercializável. A estetização da nostalgia surgiu em um momento cultural que permitiu acessar, circular e reconfigurar os traços textuais do passado em novas e dinâmicas formas, [...] que tem a nostalgia geralmente dissociada de qualquer significado específico localizado no passado. (GRAINGE, 2000, p. 33, tradução nossa).

Grainge acredita que a tendência de apropriação de referências do passado reflete mais uma nova dinâmica de sentido do que um mero sentimento de nostalgia. Tal tendência estaria associada a um novo compromisso com o passado, que passa pela reavaliação e reapresentação de suas formas, contextos e valores. A apropriação de elementos do passado, nesse sentido, fala mais sobre o presente do que sobre o próprio passado.

Entre as referências do passado que se tornaram objeto de consumo na contemporaneidade, destacam-se os produtos midiáticos. Filmes, novelas, músicas, animações, histórias em quadrinhos, entre outros produtos, são disponibilizados atualmente em vários canais: o canal Viva, da Rede Globo de Televisão, veicula programas antigos da emissora; o canal TCM, por assinatura, veicula clássicos do cinema e da televisão; o canal Boomerang 200 veicula desenhos animados antigos; o MLB Classics, canal do Youtube, disponibiliza jogos históricos de baseball; a editora Pixel lançou no Brasil coletâneas de Mandrake, Fantasma e Popeye, personagens pouco conhecidos pelas novas gerações; a editora Panini, entre outros títulos, lançou a Coleção Histórica Marvel; a editora Salvate também reeditou, como coleção, histórias clássicas dos personagens da DC Comics e da Marvel.

O interesse por esse tipo de conteúdo motivou os setores produtivos a comercializar produtos diversos com estampas de filmes, seriados, shows e personagens em quadrinhos clássicos. Em movimento semelhante ao do setor produtivo, grupos sociais e culturais passaram a se apropriar dessas referências para disseminar ideias em ambientes públicos. Nos últimos anos, é possível observar pelas ruas das cidades brasileiras, 
em especial em metrópoles como São Paulo, o excessivo uso de camisetas, por jovens e adultos, com imagens de personagens de clássicos das histórias em quadrinhos. Essa prática está diretamente associada ao consumo de bens simbólicos que, como bem lembra Featherstone (1995), está relacionado ao interesse das pessoas em compartilhar conhecimento. Na sociedade contemporânea, demonstrar um conhecimento cultural implica também a habilidade de reter informações e saber como e quando consumi-las.

Ainda que Featherstone traga essa discussão para o âmbito das diferenças entre classes sociais, a apropriação da imagem de personagens antigos revela estratégias em demonstrar um conhecimento sobre referências antigas e uma habilidade em articular os significados dessas imagens com ideias contemporâneas. Imagens apropriadas, que subvertem a lógica comercial para serem utilizadas como discursos públicos de uma geração. O problema da apropriação indevida dessas imagens em ambientes públicos, e a mistura com outros códigos culturais que se espalham pelo ambiente urbano, está no fato de que essa prática tende a alterar o valor simbólico dessas figuras.

Contudo, como destaca Featherstone (1995, p. 40), é preciso considerar que a aparente ausência de controle de certas práticas culturais esconde uma lógica própria.

podem existir "regras de desordem" cujo funcionamento permita controlar mais facilmente as oscilações entre a ordem e a desordem, a consciência de status e o jogo da fantasia e do desejo, o controle e o descontrole emocionais, o cálculo instrumental e o hedonismo - que anteriormente representavam uma ameaça ao imperativo de manter uma estrutura de identidade consistente e de recusar as transgressões.

Utilizando como base levantamento realizado para a pesquisa "Personagem em tatuagem" (CARDOSO, 2016), observou-se que existem padrões recorrentes de uso das imagens de personagens das histórias em quadrinhos em outros meios. No que se refere especificamente à forma de apresentação da figura, algumas se apresentam como práticas transgressoras - por meio da alteração de elementos visuais ou agregando elementos verbais que descaracterizam o conceito original do personagem -, mas outras "respeitam" as formas de apresentação do personagem, exibindo a figura conforme as normas estabelecidas pelos detentores do direito da imagem. É comum encontrar: cenas, gestos ou expressões que se tornaram populares; reunião dos personagens de uma mesma história - protagonista, antagonista e secundários; objetos ou símbolos que representam os personagens; capas de edições históricas de revistas; sequências de quadros com parte de história publicada; combinação da figura do personagem com textos de outros sistemas literatura, música etc.; relações estabelecidas entre a figura e o espaço que à comporta; 
figura do personagem alterada visando a transgredir as normas de utilização da imagem. Acreditamos que cada um desses padrões mostra diferentes formas de uso dos personagens que determinam distintos modos de falar sobre a cidade e sobre o cidadão.

\section{Personagens na paisagem urbana}

O bairro da Vila Madalena é um conhecido local de turismo da cidade de São Paulo, tanto por suas atrações gastronômicas e comerciais quanto por ser um espaço reconhecido como polo artístico. Entre as ruas Gonçalo Afonso e Medeiros de Alberquerque, encontra-se o Beco do Batman, uma viela que se apresenta como galeria de grafite. A travessa ganhou esse nome nos anos de 1980 em razão de uma pintura do personagem que apareceu em um dos muros. A forma de representação do Batman e a narrativa contida no gesto que exibe a embalagem de tinta spray utilizada na pintura de grafite demonstram o posicionamento transgressor e provocativo da figura.

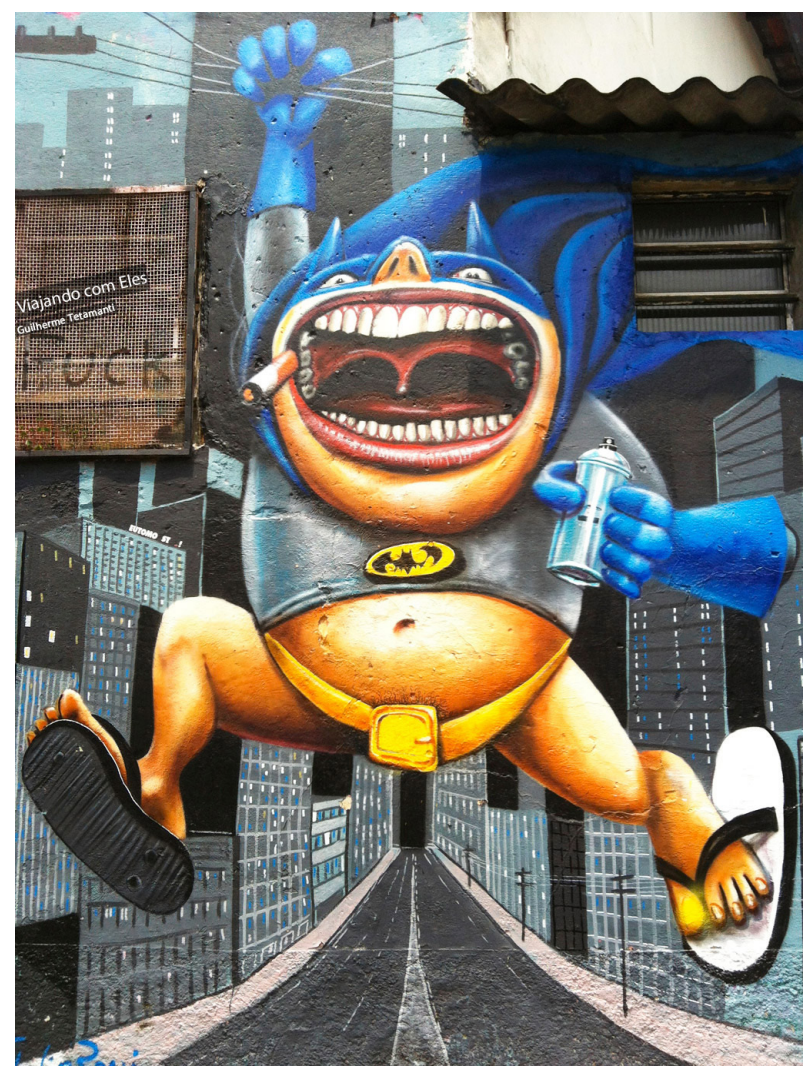

Figura 2. Grafite que deu origem ao nome do local

Fonte: Tetamanti (2013)

Se desenhos como esse eram antes percebidos como práticas marginais, atualmente são reconhecidos como formas de expressão artística que atraem visitantes ao bairro. 
Ainda assim, nessa prática há um sistema de normas que considera, em si, a subversão de outras normas, a saber: a ocupação de espaços privados e a apropriação de textos de outros sistemas culturais e comerciais. A figura do personagem, apropriada e adulterada pelo artista, convoca os observadores a tomar os muros da cidade.

Hoje, caminhando pela passagem, é possível encontrar, espalhado pelo calçamento, outra referência ao personagem da DC Comics: o símbolo do homem-morcego, conhecido por leitores e espectadores das narrativas do herói nos quadrinhos, TV, cinema ou game. O símbolo do personagem Batman ultrapassa a fantasia do céu de Gothan City e chega ao chão do beco paulistano. O grafite brinca com referências da mídia e torna o solo tela; captura a imaginação do público e converte o produto de consumo de massa em marca do local.

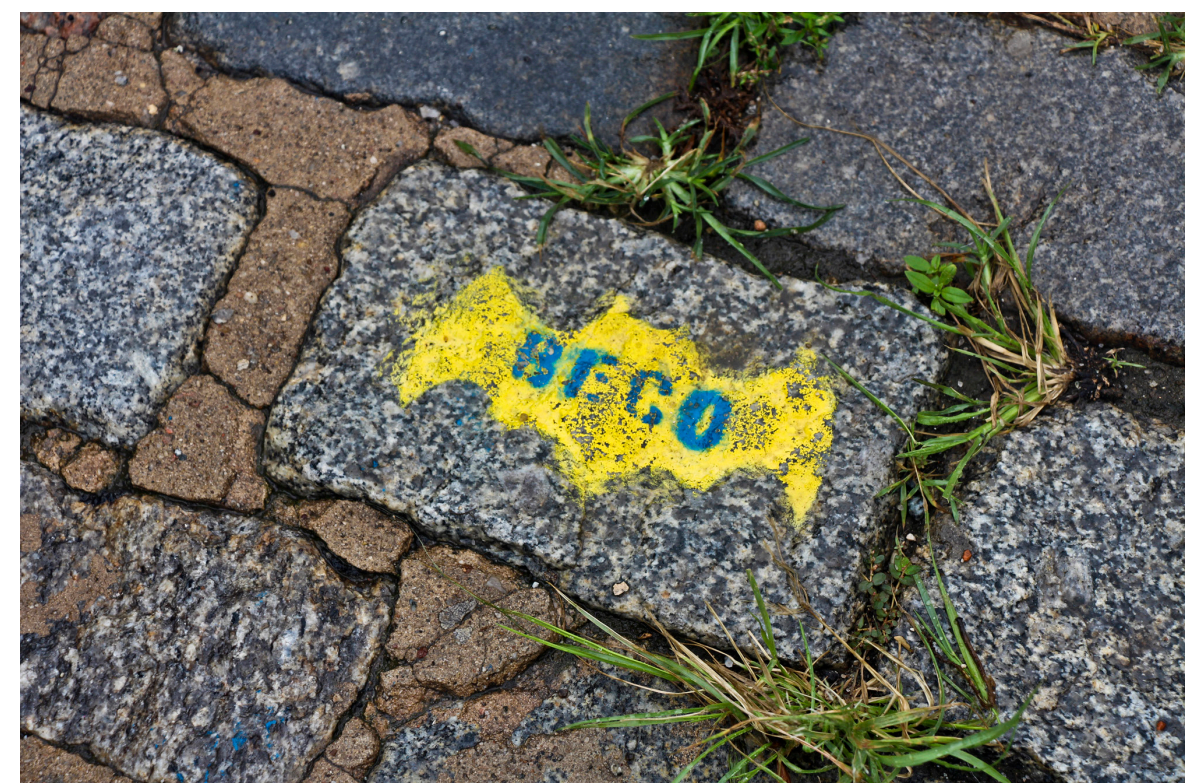

Figura 3. Pintura do símbolo do personagem Batman em paralelepípedo do Beco do Batman Fonte: Elaboração do autor (2015)

De modo geral, o grafite é utilizado como um meio de se comunicar com a cidade e com seus habitantes. Compreendido hoje como um tipo de arte, o grafite serve como forma de expressão de uma comunidade que protesta contra as condições de vida urbana, o comportamento social nas cidades ou as normas estabelecidas pelos sistemas públicos, sociais e comerciais.

$\mathrm{Na}$ Avenida do Estado, na altura do Parque Dom Pedro II, no centro da cidade de São Paulo, um grafite chama a atenção por apresentar uma figura que é parte um personagem brasileiro e parte um personagem estadunidense. O "Môckey" é composto pela cabeça da personagem Mônica, cujos direitos pertencem à empresa Maurício de Souza 
Produções, e pelo corpo do personagem Mickey Mouse, da Walt Disney Company. A figura do personagem híbrido saúda as pessoas que passam, se exibindo em sua curiosa forma.

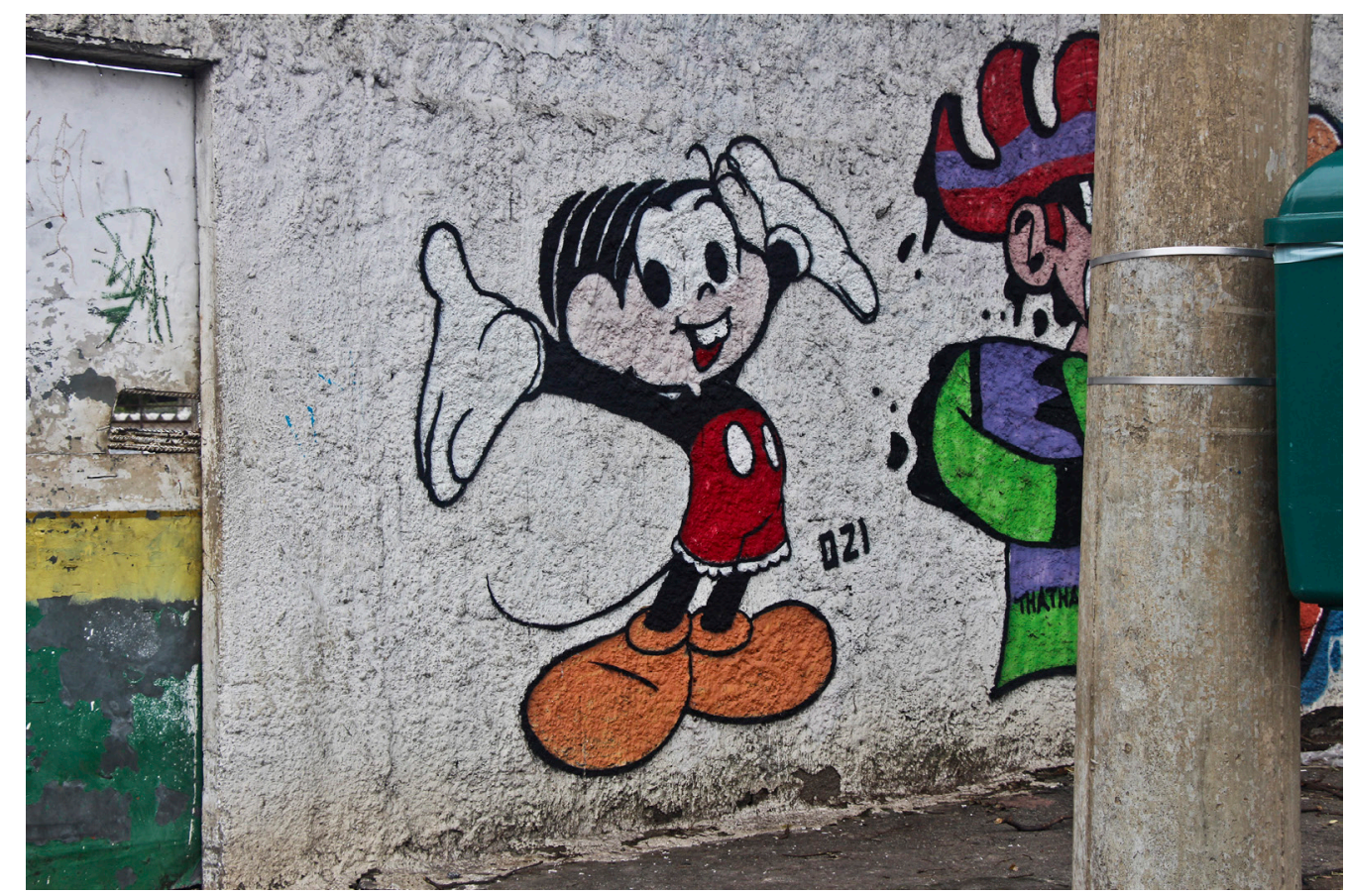

Figura 4. Grafite de personagem "Môckey"

Fonte: Elaboração do autor (2016)

A estranheza da figura visa, com toda certeza, a capturar o olhar do cidadão que passa pela rua, mas acaba também promovendo a discussão sobre as leis de direito autoral. Essa forma de transgressão combina o processo de confiança, de que fala Silverstone (2014), já que as imagens da cabeça e do corpo são apresentadas em pose e expressão já conhecidas, ao de agressão, no não respeito às regras que envolvem o uso das imagens dos personagens. A apropriação de poses e expressões já conhecidas revela a estratégia do artista de demonstrar um conhecimento sobre as referências, ao mesmo tempo que mostra uma habilidade em articular os significados dessas imagens com discussões contemporâneas. Para os transeuntes, se não surge essa reflexão, fica o olhar na figura estranha e simpática.

Nos ambientes urbanos, a exibição de intervenções em figuras de personagens se espalha também pelas bancas de camelôs ou vitrines de lojas, nas estampas em produtos diversos. Na Galeria do Rock, prédio comercial no centro de São Paulo, diversas lojas comercializam camisetas com estampas de personagens de histórias em quadrinhos, muitas delas apresentando o personagem em poses ou gestos incomuns, não autorizados pelas empresas que possuem os direitos sobre a imagem. 


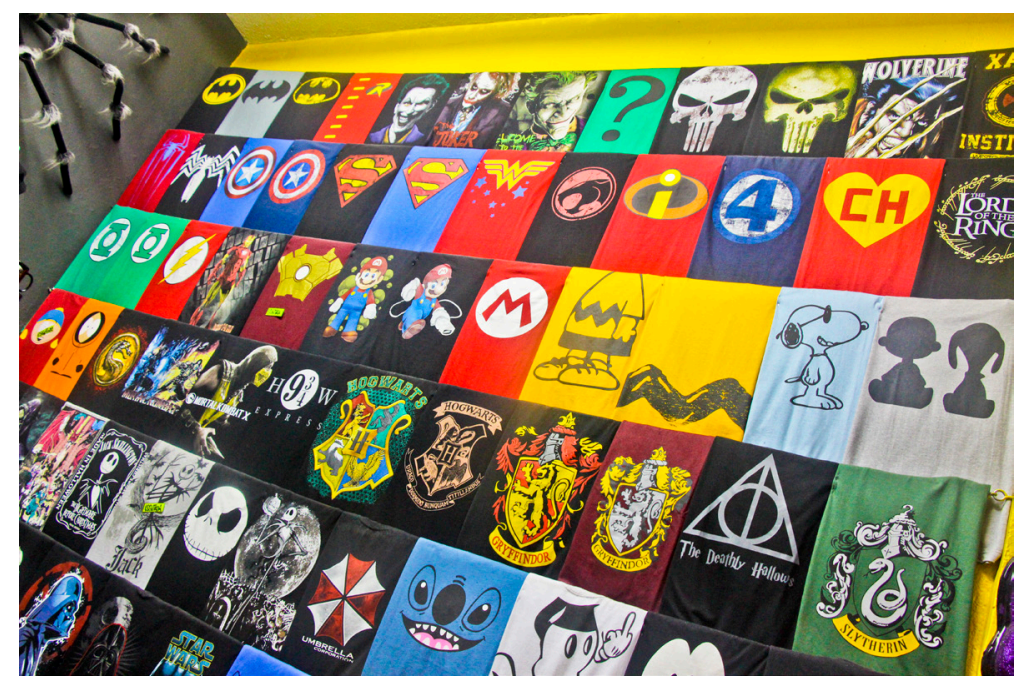

Figura 5. Vitrine de loja da Galeria do Rock

Fonte: Elaboração do autor (2016)

Muitas dessas estampas são exibidas pelas ruas por homens e mulheres adultos. São imagens que visam a atrair o olhar alheio e dizer um pouco sobre o usuário. Parafraseando Canevacci (2004, p. 43), refletem “modos de pensar, de sentir e de agir". Estão relacionadas a um sistema de valores, reconhecidos pelos grupos aos quais pertencem. Nesse contexto, o personagem transcende as narrativas seriadas e torna-se elemento que caracteriza um tipo de comportamento contemporâneo. Conforme defende Grainge (2000), essa tendência reflete, mais do que um mero sentimento de nostalgia, uma nova dinâmica de sentido. Diz mais sobre o presente do que sobre o passado.

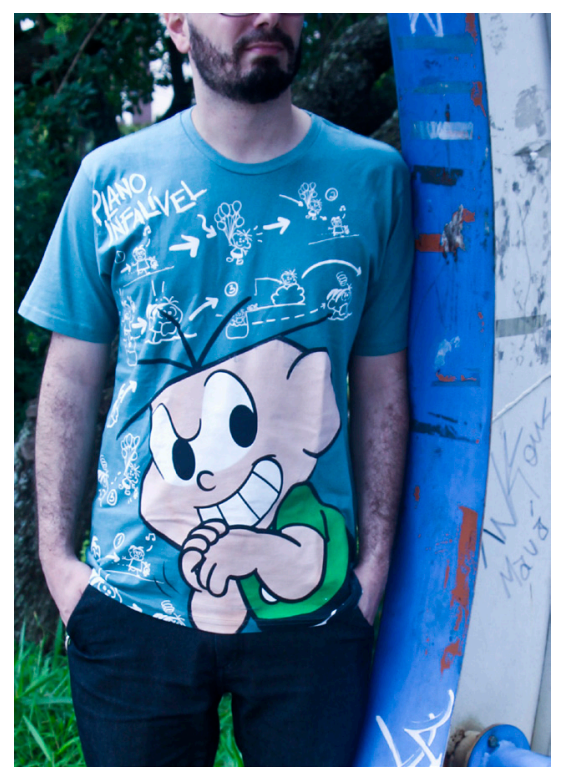

Figura 6. Camiseta com estampa do personagem Cebolinha

Fonte: Elaboração do autor (2016) 
Algumas dessas imagens funcionam como símbolos de grupos específicos. São sistemas de codificação que implicam em manter um vínculo afetivo com uma comunidade específica ou, ao contrário, assumir uma posição radicalmente contrária a um determinado grupo.

O mascote da torcida organizada Mancha Verde, fundada em 1983, foi baseado no vilão da Disney, Mancha Negra. No momento atual, a Escola de Samba Mancha Alviverde e a loja de produtos da marca Mancha Alviverde comercializam produtos diversos, entre eles camisetas, com a imagem do personagem. Tal figura não é portada por fascínio ao personagem, mas sim pelo amor ao time do Palmeiras. Assim, o olhar que fita a camisa não vê o inimigo do personagem Mickey, das histórias Disney, mas sim o time de seu coração ou o time rival. Mancha Negra, na cor verde, circula pela cidade atraindo olhares de admiração e repulsa de pessoas que talvez nunca tenham lido as histórias do personagem.

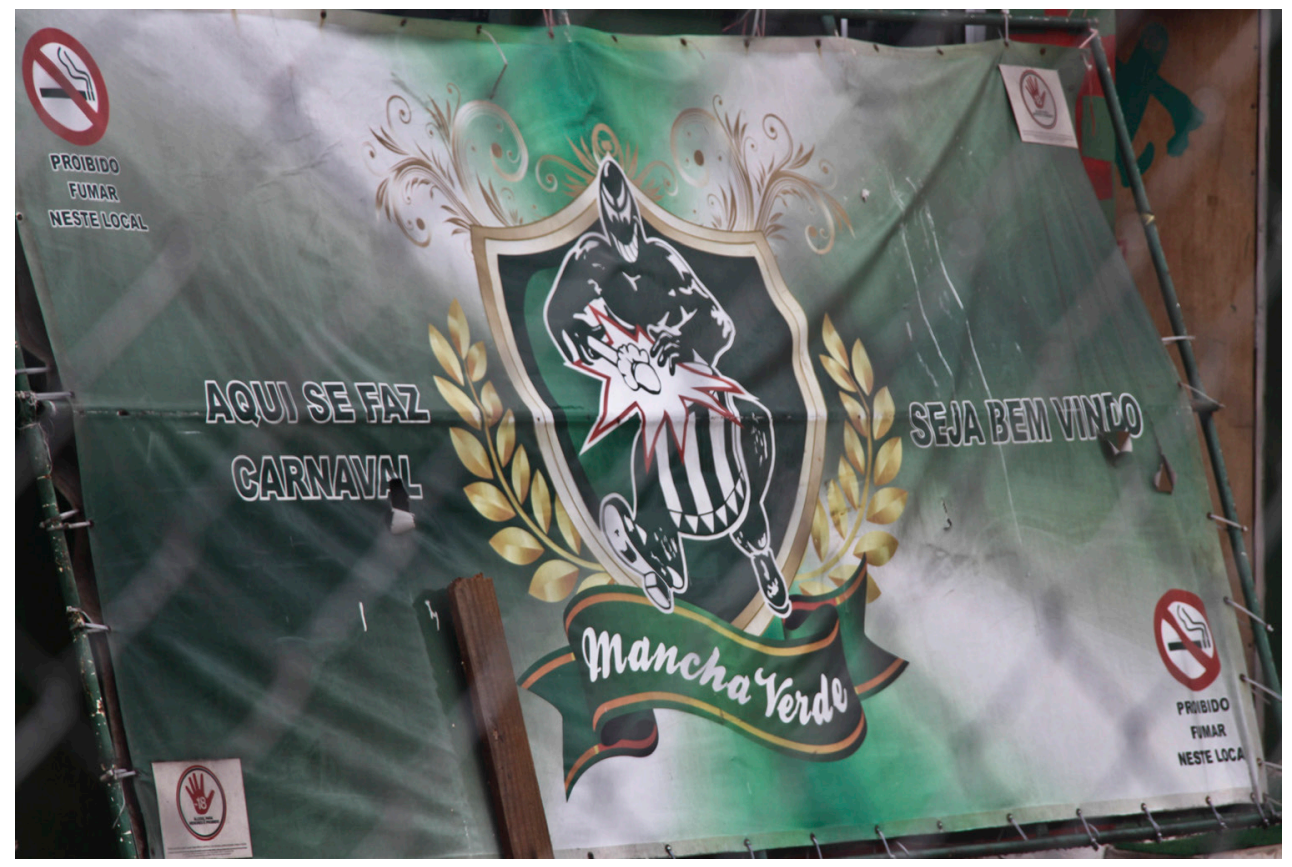

Figura 7. Bandeira da agremiação Mancha Verde

Fonte: Elaboração do autor (2016)

Entretanto, existem outras formas de apropriação desse tipo de imagem que revelam um vínculo mais forte com o próprio personagem. Geralmente, as pessoas que tatuam imagens de personagens são aficionadas por histórias em quadrinhos e desenhos animados.

Uma das pessoas entrevistas para a pesquisa "Personagem em Tatuagem"2 - um comerciante brasileiro de 42 anos residente da região do Grande ABC Paulista, que

2 Entrevista realizada em 16 de setembro de 2015.

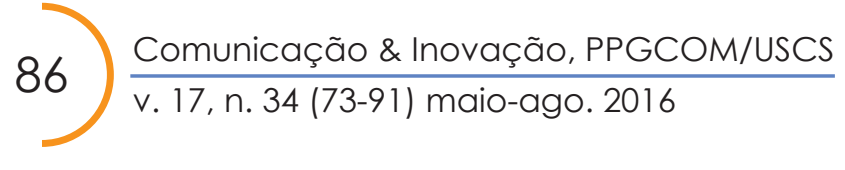


chamaremos aqui de PA - possui mais de cento e vinte tatuagens de personagens e coleciona objetos diversos relacionados ao tema. A maior parte das tatuagens do comerciante é de figuras dos desenhos dos estúdios Hanna Barbera, veiculados no Brasil a partir da década de 1960. Para expressar sua afeição pelos personagens, PA faz questão de manter os gestos ou expressões que se tornaram populares e caminhar pela cidade com camiseta regata branca para que as pessoas possam admirar sua coleção. Para ele, a decisão de tatuar personagens não foi motivada por uma tendência: "Não era uma questão de moda, eu queria fazer alguma coisa que me lembrasse... que me fizesse feliz".

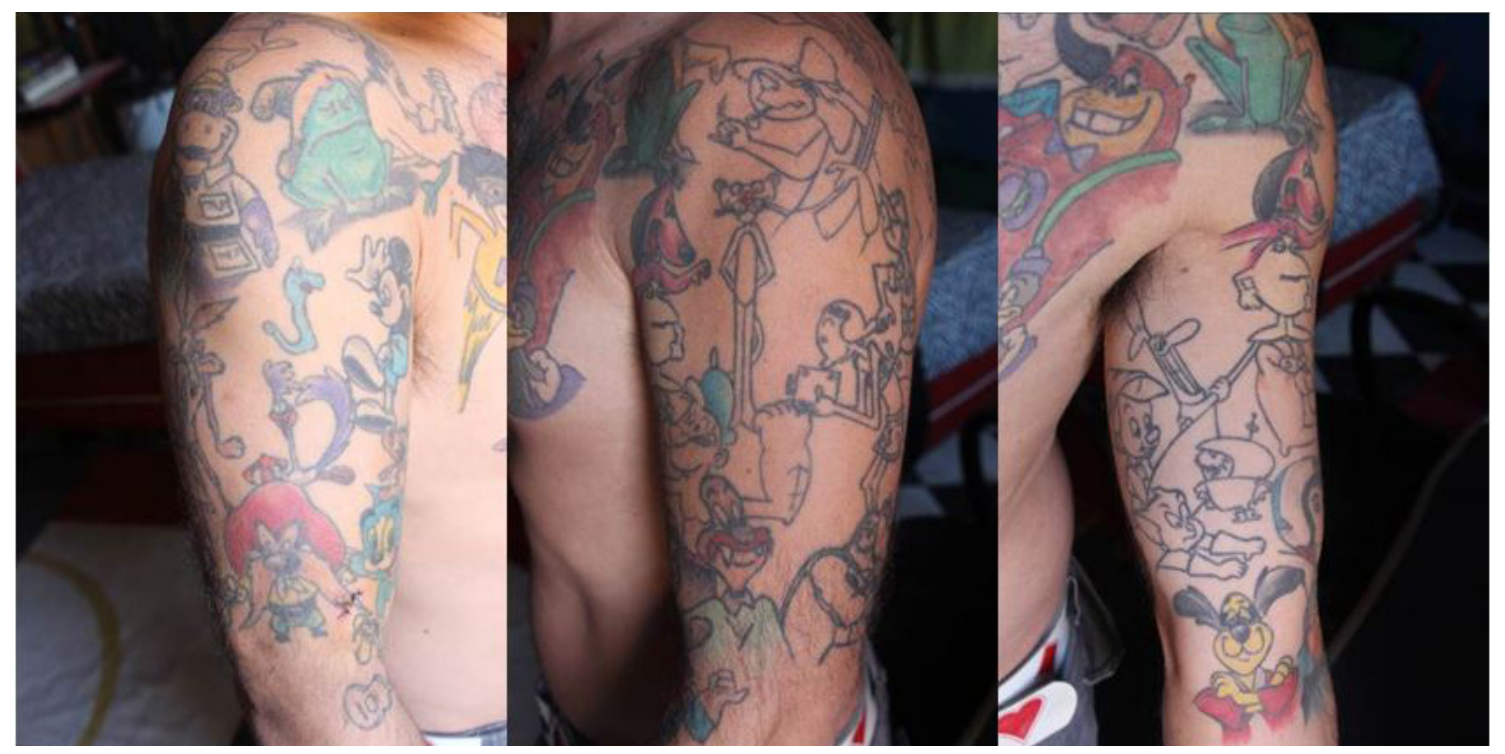

Figura 8. Vistas do corpo de PA

Fonte: Elaboração do autor (2015)

Muito desse interesse, que se mantém na idade adulta, inicia na infância. Segundo PA, a motivação para realizar a primeira tatuagem de personagem está intimamente ligada à sua infância:

É uma infância meio trágica, de família, separação [...]. Então a única coisa que eu tinha mesmo era uma televisão. [...] e os desenhos animados era uma forma da gente ficar ali prendido na alegria. [...] o desenho era uma coisa que não representava muita agressividade e que me fazia dar muita risada [...] eu me espelhava muito nisso. (informação verbal).

De acordo com Fruh e Thomas (2012), a tatuagem se torna capaz de unificar vertentes díspares de uma longa vida, unindo passado e futuro. $\mathrm{O}$ que isso sugere, para os autores, é que a tatuagem pode ter um efeito de ancoragem, amarrando pontos entre 
passado, presente e futuro na formação de uma resposta para a questão de quem eu sou. No caso da tatuagem de personagem, tudo indica que é o desejo de preservar, ou superar, a memória de uma infância: "quando eu tatuava e me olhava no espelho parecia que eu tinha completado algo na minha vida. Tinha jogado fora algum problema pessoal lá de trás" (PA, informação verbal).

A tessitura das narrativas entrelaça elementos de vivência com elementos do imaginário. Ao mesmo tempo que colabora para o desenvolvimento de uma identidade, revela como o portador entende a si e ao mundo. Essas imagens, no corpo e nas roupas, de alguma maneira, dialogam com as imagens nos muros e nas vitrines. Revelam uma tendência de nosso tempo.

As personagens também atravessam as ruas das cidades em eventos culturais e manifestações políticas. Assim como o carnaval, os eventos de cosplay motivam os participantes a se fantasiar - essas pessoas brincam com elementos da mídia e debocham do comportamento da sociedade. Ainda que muitos desses eventos aconteçam em lugares fechados, é comum encontrar pessoas nas mediações que incorporam a imagem e o comportamento de seus personagens preferidos.

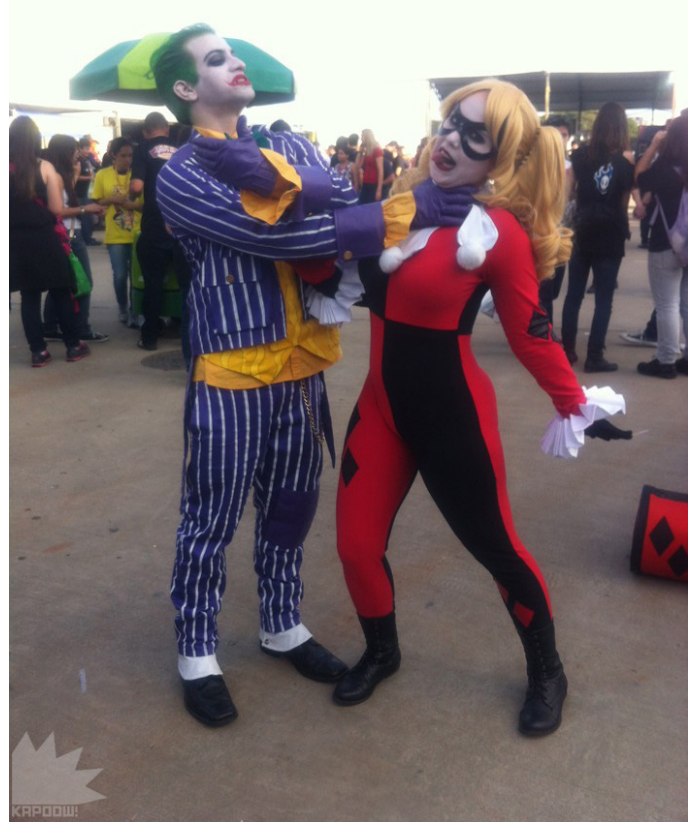

Figura 9. Anime Friends (São Paulo, 2015)

Fonte: Site Kapoow Gamehall UOL ${ }^{3}$

3 Disponível em: <http://kapoow.gamehall.uol.com.br/2015/07/13/galeria-de-fotos-anime-friends-2015/anime-friends-2015_cosplays-15/>. Acesso em: 05 fev. 2016.

$88 \frac{\text { Comunicação \& Inovação, PPGCOM/USCS }}{\text { v. 17, n. } 34 \text { (73-91) maio-ago. } 2016}$ 
Também fazendo uso das referências dos quadrinhos, mas com o objetivo de protestar, jovens vestiram a máscara do personagem $\mathrm{V}$, da série $V$ de Vingança (1982), para reclamar das ações dos governos em diversas partes do mundo, inclusive em São Paulo. O personagem, nesse momento, virou símbolo do protesto e acabou se tornando estampa de camiseta que simboliza a insatisfação com os governantes e as políticas públicas.

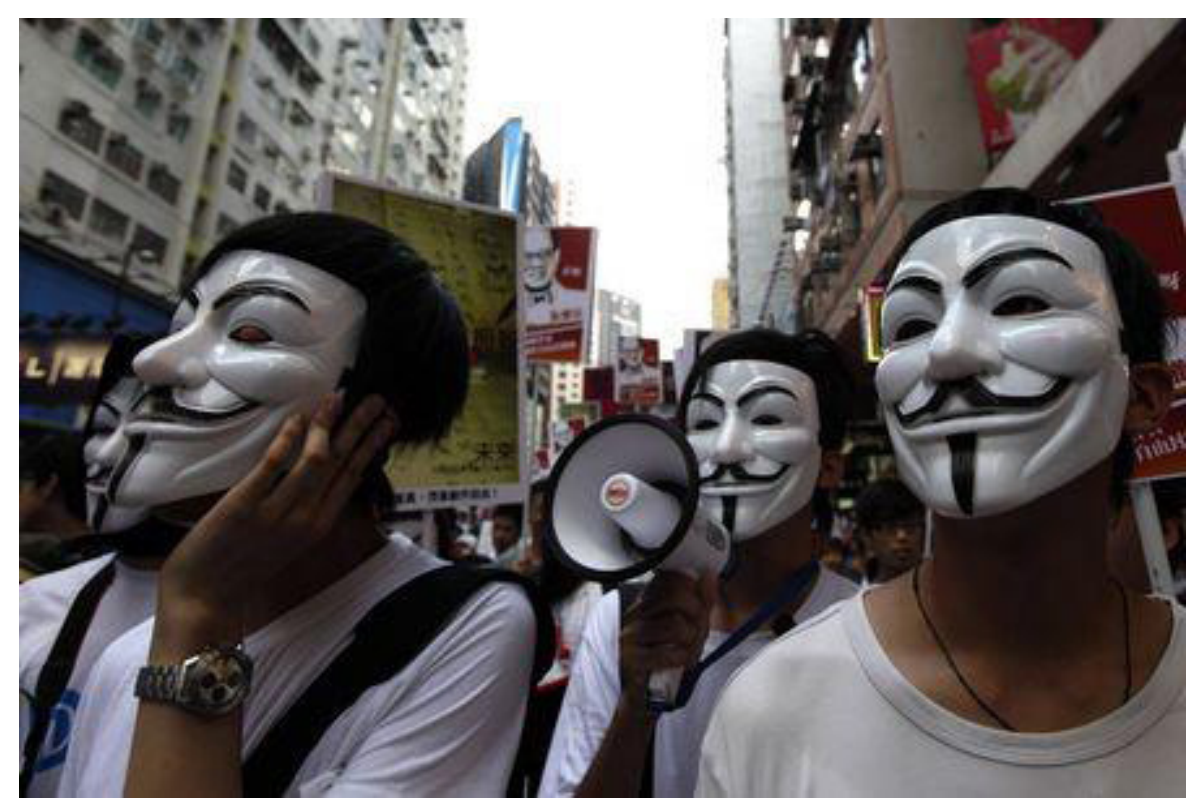

Figura 10. Máscara do personagem $V$ utilizada em passeata Fonte: MÁSCARA (2001)

As maneiras como essas imagens são tiradas de seus contextos, por pessoas, comunidades, empresas ou organizações não governamentais, faz que elas adquiram um novo sentido. As práticas urbanas - no simples caminhar do cidadão pelas ruas, na marcha da passeata que atravessa a cidade, no comércio irregular que encontra espaço nas brechas da cidade ou nas intervenções artísticas que ocupam muros e paredes das edificações tornam os personagens, originários das narrativas impressas ou audiovisuais, parte dos discursos da cidade e sobre a cidade, parte dos discursos do cidadão e sobre o cidadão.

\section{Considerações finais}

Fazendo este breve levantamento das formas de apropriação das imagens de personagens em práticas cotidianas no ambiente urbano, surge a hipótese de que a personalidade do personagem - os aspectos visíveis que compõem seu caráter individual, e as qualidades que o diferenciam de outros personagens - é o que realmente interessa a quem utiliza tal tipo de signo para construir seu discurso. 
Tais características, que são análogas ao conjunto de aspectos psíquicos ou comportamentais humanos, são desenvolvidas nas narrativas midiáticas. Nelas, o caráter individual do personagem é construído por meio dos discursos e ações do protagonista, antagonista e personagens secundários. A repetição desses caracteres nos diálogos, monólogos e ações servem para estruturar uma personalidade coerente e simplificada.

Como os discursos, ações e conflitos tendem a se repetir nas histórias em quadrinhos e desenhos animados, as estruturas narrativas exigem do personagem uma regularidade de comportamento. Algumas falas, gestos ou expressões se repetem em todas as histórias. São justamente essas poses, gestos, expressões e falas, já conhecidas pelas pessoas, que tendem a definir as personalidades dos personagens. Por isso, é natural que certos padrões de imagem apareçam em maior quantidade nas estampas de camisetas, mochilas e outros tipos de suporte.

Da mesma maneira que certas marcas fazem uso dessas características dos personagens em seus produtos, indivíduos, comunidades e organizações se apropriam dessas imagens e de seus valores simbólicos para protestar, comemorar, delimitar um local, identificar um grupo e difundir suas ideias pelos espaços públicos. Como tais ações são praticadas por pessoas com maioridade, é natural que muitas das referências utilizadas sejam de décadas passadas. Além do mais, muitas dessas imagens veiculadas antigamente em revistas ou televisão continuam circulando pela internet, em programas e canais de televisão fechados e em publicações de coletâneas de clássicos dos quadrinhos. Nesse sentido, é natural que a tendência retrô, iniciada na década de 1980, tenha motivado o resgate dessas imagens. No entanto, a questão mais interessante nesse processo é o fato de a reconfiguração e ressignificação dessas imagens servir a discursos do presente.

Esse fluxo de sentido entre as narrativas midiáticas, que se tornam símbolos culturais, e as práticas urbanas contemporâneas se apresenta como uma sobreposição de discursos, que refletem nossa forma de compreender a realidade que nos cerca. Na cidade que captura nosso olhar, assim como nas pessoas que circulam pela cidade e capturam nosso olhar, existem personagens que brincam como nossa imaginação, que trazem para São Paulo e outras cidades um pouco das histórias de Patópolis ou Metrópolis. Essas histórias são também nossas histórias, e precisam ser lidas.

\section{Referências}

CANEVACCI, M. A cidade polifônica: ensaio sobre a antropologia da comunicação urbana. São Paulo: Studio Nobel, 2004.

CARDOSO, J. B. F. Tatuagens e histórias de vida: o personagem na construção da identidade. In: COMPÓS, GT PRÁTICAS INTERACIONAIS E LINGUAGENS NA COMUNICAÇÃO, 25., 2016, Goiânia.

\footnotetext{
$90 \frac{\text { Comunicação \& Inovação, PPGCOM/USCS }}{\text { v. 17, n. } 34 \text { (73-91) maio-ago. } 2016}$
} 
Anais... Goiânia: UFG, 2016. Disponível em: <http://www.compos.org.br/biblioteca/gt_pilc_cardoso_3419.pdf>. Acesso em: 31 maio 2016.

CARDOSO, J. B. F.; SANTOS, R. E. There's life in other systems: the comic character outside narratives. International Journal of Comic Art, v. 17, n. 2, p. 147-160, 2015.

FEATHERSTONE, M. Cultura de consumo e pós-modernismo. São Paulo: Studio Nobel, 1995.

FRUH, K.; THOMAS, E. Tattoo you: personal identity in ink. In: ARP, R. (Ed.). Tattoos - philosophy for everyone: I ink, therefore I am. Oxford: Wiley-Blackwell, 2012. p. 83-95.

GORDON, I. Comic strips and consumer culture: 1890-1945. Washington: Smithsonian Institution, 1998.

GRAINGE, P. Nostalgia and style in retro America: moods, modes and media recycling. Journal of American Culture, v. 23, n. 1, p. 27-34, 2000.

LEFEBVRE, H. O direito à cidade. São Paulo: Centauro, 2001.

MÁSCARA de personagem de quadrinhos vira marca de protestos pelo mundo. Extra, 1 jul. 2011. Disponível em: <http://extra.globo.com/noticias/mundo/mascara-de-personagem-de-quadrinhos-vira-marca-de-protestos-pelo-mundo-2148104.html>. Acesso em: 31 maio 2016.

SILVERSTONE, R. Por que estudar a mídia? São Paulo: Loyola, 2014.

TEtamanti, G. O incrível e colorido Beco do Batman. Alma Paulista, 2 jul. 2013. Disponível em: $<$ http://www.almapaulista.com.br/o-incrivel-e-colorido-beco-do-batman/>. Acesso em: 31 maio 2016. 